\section{Invasive aspergillosis of the brain: Improvement with lyposomal amphoterecin B and itraconazole}

Sir,

Intracranial aspergillosis is often an extension from paranasal sinuses and is usually resistant to medical or surgical therapy. ${ }^{[1,2]}$ We report a case that showed good response to a combination of liposomal amphotericin $B$ and itraconazole after having no response to amphotericin B deoxycholate.

A 43-year-old male presented with fever, diplopia, headache, left focal seizures and weakness on the left half of the body of one month duration and nasal obstruction with difficulty in breathing due to nasoethmoidal mass of two weeks duration. The mass was excised and found to have dichotomously branched septate hyphae with conidial heads suggestive of Aspergillus fumigatus on histopathology. A few years back he had undergone balloon mitral valvotomy for rheumatic mitral stenosis and his cardiac status was stable since then. On admission, he had moderate fever of about $100^{\circ} \mathrm{F}$ with no lymphadenopathy. On neurological examination patient was drowsy, not responding to verbal commands but localizing the painful stimuli. Proptosis was present on the right side. Neck was supple. There was face-arm-leg weakness $(2 / 5$ on MRC scale), spasticity, brisk reflexes and extensor plantar response on the left side. His serology for HIV was negative. The MRI revealed mixed intensity heterogeneous mass lesion on T2 weighted image with thick irregular enhancement on T1 contrast image. The mass extended from the sphenoid sinus to the left frontal and parietal lobe and then through the anterior part of the corpus callosum to the contralateral frontal lobe [Figures 1a and $1 \mathrm{~b}$ ].

Patient was given two six-week courses of amphotericin B deoxycholate. No improvement in symptoms or regression of mass was found on MR imaging. He was then treated with liposomal amphotericin $\mathrm{B}$ given

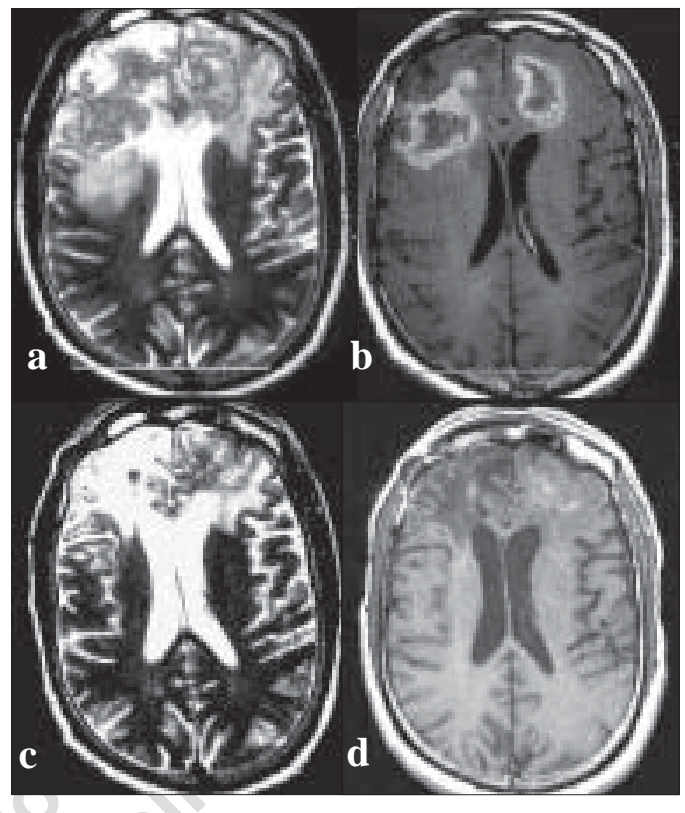

Figure 1: T2 weighted ( $a$ and $c$ ) and T1 weighted contrast (b and d) axial images of the brain showing pre-treatment mixed hypo- and hyperintense mass lesion involving the right fronto-parietal region with spread to opposite frontal lobe (a), which shows thick irregular enhancement (b). Post-treatment images taken six months later showed shrinkage of the mass (c) with only a few small areas of enhancement (d)

intravenously $5 \mathrm{mg} / \mathrm{kg}$ per day for six weeks along with oral itraconazole $200 \mathrm{mg}$ daily. There was gradual improvement in his consciousness by third third week and his power improved to $4+$ on 0-5 MRC scale with decrease in spasticity. His proptosis improved and he walked without support. Oral itraconazole was continued for four months during which he resumed his office and performed mental work. The MRI showed reduction of lesion to nearly half of its original size on T2 image with only a few specks of enhancing areas seen within the lesion on T1 contrast image [Figures 1c and $1 \mathrm{~d}]$. The areas which did not enhance but showed T2 hyperintensities, were presumed largely to be due to healing by gliosis as there was shrinkage of the brain tissue evidenced by prominent cortical sulci.

The mortality is reported to be nearly $100 \%$ in immunocompromised patients, ${ }^{[3]}$ but some immunocompetent patients have survived this disease with antifungal chemotherapy and surgical resection. ${ }^{[4]}$ Earlier reports of good response to liposomal amphotericin $\mathrm{B}^{[4]}$ and itraconazole $\mathrm{e}^{[4,5]}$ prompted us to put our patient on a combination chemotherapy and the response was good as assessed by clinical and imaging modalities. Till a better treatment regimen is found, this combination chemotherapy may be used to treat intracranial aspergillosis with satisfactory outcome.

\section{Sunil Pradhan, Ramakant Yadav}

Department of Neurology, Sanjay Gandhi Postgraduate Institute of Medical Sciences, Raebareli Road, Lucknow - 226 014, India.

E-mail:drspradhan@rediffmail.com 


\section{References}

1. Nadkarni T, Goel A. Aspergilloma of the brain: An overview. J Postgrad Med 2005;51:S37-41.

2. Dubey A, Patwardhan RV, Sampth S, Santosh V, Kolluri S, Nanda A. Intracranial fungal granuloma: Analysis of 40 patients and review of the literature. Surg Neurol 2005;63:254-60.

3. Denning DW. Therapeutic outcome in invasive asperigillosis. Clin Infect Dis 1996;23:608-15.

4. Coleman JM, Hogg FF, Rosenfeld JV, Waters KD. Invasive central nervous system aspergillosis: Cure with liposomal amphotericin B, itraconazole and Radical surgery- case report and review of the literature. Neurosurgery 1995;36:858-63.

5. Renard JF, Onnient Y, Proust F, Massardier E, Raspaud C, Nouvet G, et al. Neuroaspergillosis and brain tuberculosis in an immunocompetent patient with good outcome. J Neurol Neurosurg Psychiatry 1998;64:4112. 